\title{
Diagnostic Problems in Huntington's Chorea and Tardive Dyskinesia
}

\author{
Martin Buxton
}

W

HEN THE CLINICIAN encounters a demented adult patient with choreiform movements he is likely to think of the diagnosis of Huntington's chorea. However, when the family is inconclusive and the patient has been medicated with neuroleptic agents, the diagnosis of tardive dyskinesia, the late and frequently permanent complication of neuroleptics, must also be considered. How confidently can this differential diagnosis be made? An answer to this question will be sought by reviewing and comparing (1) the significant epidemiologic data, (2) the clinical descriptions, (3) the psychologic symptomatology, (4) associated drug use, (5) the speculated pathophysiologic mechanisms, (6) the presumptive pharmacologic diagnostic tests, (7) the neurochemical findings, (8) the radiographic and postmortem findings, and (9) other findings of both Huntington's chorea and tardive dyskinesia.

The following case history illustrates the difficulty that is sometimes encountered when attempting to differentiate between Huntington's chorea and tardive dyskinesia.

A 40-year-old married Caucasian woman came to the emergency room complaining of increasing nervousness, inability to control her temper, and involuntary movements, all of which had become progressively worse over the preceding several years.

The patient was one of four children; her 22 - and 26 -year-old brothers were asymptomatic. She did, however, have a 39-year-old brother who was described as being an alcoholic and who had had several hospitalizations for this problem. The patient's mother was alive and well at age 60, but her father had died at age 67 at a nearby state psychiatric hospital. The father's old hospital records revealed his having been diagnosed differently several times, e.g., character disorder, paranoid schizophrenic, chronic organic brain syndrome, and chronic undifferentiated schizophrenic. He had been treated for an unknown period of time with thioridazine $100 \mathrm{mg}$ q.i.d. On one physical examination a few years before his death, he had been noted to be ataxic and to have a slight tremor. A postmortem examination revealed left upper lobe pneumonia, advanced bilateral pulmonary emphysema, arteriosclerotic heart disease, and fatty infiltration of the liver. Unfortunately, his cranium was not opened. The father was one of ten siblings; the others by history did not reveal any pathology, but four died accidental premature deaths, two had alcoholic problems, one died of an unspecified cancer, and two were reportedly well adjusted and in good hcalth.

During the clinical examination, the patient's tongue protruded, she had a facial grimace, and her head rolled first to the side and then backward. At other times her upper limbs had the appearance of flying through the air, and her trunk would gyrate. She had a prancing steppage in her gait, but did not fall despite what appeared to be poor balance while walking. Neuropsychiatric examination revealed her to be oriented to person and place, but she did not know the date. She made frequent errors in calculations and could not spell the word "world" backward. She was able to abstract from proverbs,

From the Children's Psychiatric Hospital, University of Michigan Medical Center, Ann Arbor. Mich.

Martin Buxton, M.D.: Chief Resident of Youth Services, Department of Psychiatry. Children's Psychiatric Hospital, University of Michigan Medical Center.

Reprint requests should be addressed to Martin Buxton, M.D., Children's Psychiatric Hospital, University of Michigan, Ann Arbor, Mich. 48104.

(C) 1976 by Grune \& Stratton, Inc. 
but demonstrated extreme denial of her movement disorder. Despite her severe dysarthria, she could repeat five numbers forward and three numbers backward. The patient complained of difficulty in her short-term memory, as she had been forgetting phone numbers and things on the stove. During the examination she wasn't able to recall the name of three cities after $5 \mathrm{~min}$. Cranial nerve testing was within normal limits except for failure to converge her vision and the absence of optokinetic nystagmus. Sensory examination showed decreased proprioception in all extremities. She made frequent errors in graphesthesia. Motor examination showed grossly choreiform movements as described above. She was able, however, to walk on her heels and toes. Cerebellar examination showed her finger-to-nose testing to be bilaterally abnormal. Heel-to-shin testing was normal. Her ability to tandem-walk was poor, and rapid alternating movements were decreased, as were fine coordinated movements of the hands. Deep tendon reflexes were not increased; Babinski and Hoffman reflexes were absent. On physical examination her heart, lungs, and abdomen were non remarkable. On history the patient claimed to have been taking Triavil 4-25 mg q.i.d. intermittently for the previous 7 years, ever since she had become depressed and irritable. A pneumoencephalogram of the patient revealed slight cerebcllar atrophy and complete absence of the caudate nucleus. The patient was diagnosed as having Huntington's chorea and was treated with major tranquilizers.

Thus, this 40-year-old female, who showed progressive deterioration in her ability to function and who manifested involuntary motor movements, was diagnosed as having Huntington's chorea. But were her psychologic symptoms part of the presentation of this disease or were they nothing more than symptoms of depression and anxiety? Were her involuntary movements part of the presentation of Huntington's chorea or were they tardive dyskinesias secondary to her use of neuroleptic medications? Did her father have Huntington's chorea or did he have some other disorder such as schizophrenia?

\section{EPIDEMIOLOGIC DATA}

George E. Crane, in his article "Persistent Dyskinesia," states that the early findings and reviews of tardive dyskinesia reported it more likely to occur in females, in the elderly, and in brain-damaged patients. He went on to point out, however, that there is some disagreement regarding these statements in the more recent literature.

The studies by Degkwitz, ${ }^{2}$ Heinrich et al., ${ }^{3}$ Kennedy et al., ${ }^{4}$ Turunen and Achte, ${ }^{5}$ Villeneuve et al., ${ }^{6}$ Lehmann et al., ${ }^{7}$ and Brandon et al. ${ }^{8}$ have found females to be more frequently affected, while studies by Crane, ${ }^{9,10}$ Hippius and Lange, ${ }^{11}$ and Fann et al. ${ }^{12}$ have not found females more frequently affected.

The variable of age is believed to be an important contributing factor in the development of tardive dyskinesia, but at least two authors do not regard it as such. Crane suggests that this discrepancy may be due to complex interactions between drug treatment and the characteristics of the population studied. As an example of this, he cites a study of his own on a selected sample of patients under 56 years of age in which he found that age was positively related to dyskinesia in only those receiving very high doses of trifluoperazine hydrochloride. ${ }^{10}$ Another study by the same author mentioned below further substantiates age as a significant variable.

Several authors have reported that preexisting brain damage and previous treatment with electroshock or insulin coma do not play a role in the development of tardive dyskinesia. ${ }^{8,12.13}$ However, Edwards, ${ }^{14}$ contradicting his own earlier findings, ${ }^{15}$ reported a highly significant difference between brain-damaged and non-brain-damaged patients in this respect. Crane ${ }^{16}$ reported a survey of 350 patients from chronic hospital wards in whom he had attempted to relate the fre- 
quency of tardive dyskinesia to age, sex, duration of continuous hospitalization, current treatment, and disorders of the central nervous system; he found that of these variables only age was positively related to dyskinesia at a high level of significance.

Crane has also reported that the incidence of tardive dyskinesia varies from $0.5 \%$ to $40 \%$ in the populations surveyed by 17 investigators. ${ }^{1}$ He attributed this variance to a number of factors: the methods used in obtaining information, the definition of the syndrome, the type of patient population studied, and most significantly the differences in clinical assessment of sy mptoms.

Reviewing the epidemiology of Huntington's chorea, most studies agree that the prevalence of this disease ranges from 4 to 7 per 100,000 population. ${ }^{17}$ The early notion that Huntington's chorea is virtually absent among Jews is no longer substantiated, as Myrianthopoulos found the prevalence among Jews to be at least 1 in $28,000 .{ }^{17}$ This disease is found with varying prevalence in various parts of the world. ${ }^{18}$

Epidemiologic comparisons with schizophrenia, the illness that is most likely to require the use of neuroleptics, reveals some intriguing data. In both Huntington's chorea and schizophrenia the risk of onset is minimal after the age of 55 , and the earlier the onset the poorer the prognosis. ${ }^{19} \mathrm{~A}$ genetic cause and a monogenic, autosomal-dominant mode of transmission seem to be established in Huntington's chorea, ${ }^{19}$ while an increased risk for schizophrenia among the offspring of schizophrenics has also been established. ${ }^{20}$ The importance of a conclusive family history in making the diagnosis of Huntington's chorea is reflected by the paucity of reported cases of choreics born to nonchoreic parents. ${ }^{21}$

\section{CLINICAL DESCRIPTIONS}

According to a special report by the American College of Neuropsychopharmacology-Food and Drug Administration Task Force," the "bucco-linguomasticatory" (BLM) triad are the most frequently described symptoms of tardive dyskinesia. This triad consists of sucking and smacking movements of the lips, lateral jaw movements, and tongue movements described as thrust, roll, or fly-catching. A chewing-the-cud type of movement can be seen when the mouth is kept closed and the tongue thereby hits the side of the cheek. Other modes of onset besides the BLM syndrome can be found, e.g., tic-like movements of the lips and eyes. As is also the case in Huntington's chorea, the oral and other movements may worsen under emotional stress and will disappear during sleep. Significant to the scope of this paper is the finding that the extremities of patients with tardive dyskinesias sometimes show choreiform movements. These are variable, purposeless, and involuntary quick movements that frequently increase with attention. Other authors have described the fingers as exhibiting a guitarplaying movement. ${ }^{23}$ When the abnormal motility of the fingers or toes becomes rhyth mical, a tremor-like movement can be seen if the hand or foot is rested on a firm surface. The feet and ankles are also affected at times, and as they rotate in all directions they sometimes assume an equinovarus position. Thigh movements, alternating adduction and abduction, often accompany movements in the distal portions of the lower extremities. Abnormal diaphragmatic motility can cause respiratory dyskinesia. ${ }^{23}$ Infrequently, the spine may demonstrate a to-and-fro 
clonic movement in the anteroposterior direction..$^{22}$ Thus the movements found in tardive dyskinesia span the whole body and can include one or many of the same movements usually associated with Huntington's chorea.

The similarity described above is highlighted by Klawans' statement that "patients with Huntington's chorea often present with movements that are similar in appearance to tardive dyskinesias." 24 Furthermore, there is considerable variation in the movement disorders of patients with Huntington's chorea. An appreciation of this variation can be gained by reviewing the literature of this disorder and noting the different forms or types that have been described on the basis of clinical presentation. A rigid and akinetic or juvenile type, a status subchoreaticus type, a chorea Huntington sine chorea type, and a hyperkinetic hypotonic adult type have all been described ${ }^{25}$ The variation in movement disorders in Huntington's chorea can also be appreciated in the new classification scheme suggested by Stevens in his tabular summary of the various clinical categories of patients with Huntington's chorea. ${ }^{25}$

\section{PSYCHOLOGIC SYMPTOMS}

Disordered behavior, and in its extreme, dementia, are readily associated with the clinical course of Huntington's chorea. However, three different sets of disordered behavior have been described either coincident with or following the appearance of the chorea. ${ }^{19}$ The first set is composed of behavior that is attributable to a dementia and includes impaired memory, impaired concentration, impaired orientation, and confusion. The second set consists of aberrant forms of behavior that are nonspecific but that involve a lesser deterioration of the brain. Included in this set are emotional lability, cuphoria or depression, restlessness or apathy, irritability, and self-neglect. The third set consists of behavior that is similar to the behavior found in schizophrenia. Included are inappropriate sexual behavior, preoccupation with the imputed sexual misbehavior of others, delusional persecutory beliefs, delusions of grandeur, and apparent hallucinations. Behavior of this third set often leads to a primary diagnosis of mania, psychotic depression, or paranoid schizophrenia. ${ }^{19}$ However, even when the choreic movements are present, a diagnosis of schizophrenia could be made by regarding these symptoms as stereotypic behavior or tics or, as pertinent to this paper, schizophrenia with tardive dyskinesia. Furthermore, episodes of hallucinatory and paranoid assaultive behavior have been frequently reported in patients with Huntington's chorea. ${ }^{19}$ Significantly, there does not appear to be a pattern or even an often repeated time relationship between the onset of the chorea and psychosis, and therefore it is possible in the early stages to misdiagnose an organic disorder as a functional disorder. ${ }^{19}$ If the contention of these authors that Huntington's chorea can have a schizophrenic appearance, a schizophrenic onset, or even be accompanied by schizophrenia is true, the psychologic presentation of the patient may at times be of little help in differentiating between these disorders.

\section{ASSOCIATED DRUG USE}

"The high incidence of involuntary movements in drug-treated populations, and the relative rarity of such abnormalities in similar untreated populations provide compelling evidence to indicate that tardive dyskinesia is related to the 
use of phenothiazines or similar agents." ${ }^{11}$ According to Ayd ${ }^{26}$ the earliest onset of tardive dyskinesia was between 3 and 6 months after the beginning of drug therapy. While two other studies ${ }^{3,27}$ have also found dyskinesias in patients who had been on neuroleptics for 4 and 6 months, the majority of patients with dyskinesias have been on these drugs for over 2 years. ${ }^{1}$ This question about duration of drug use and onset of tardive dyskinesia is further complicated by the belief that some patients can actually have the disorder before it is recognized, as it is believed that the disorder can be masked while the patient is still taking the medication. ${ }^{1}$

Further evidence to support the contention that the differential diagnosis between Huntington's chorea and tardive dyskinesia can be difficult is provided by Ringel et al. ${ }^{28}$ According to their survey, the majority of Huntington's patients are being treated with neuroleptic medications. Of the 306 patients surveyed, 192 were being medicated with neuroleptics. Haloperidol and chlorpromazine were most commonly used for these Huntington's chorea patients. These drugs are also widely prescribed for the general psychiatric population and have been implicated in cases that later developed tardive dyskinesia. ${ }^{29}$

\section{PATHOPHYSIOLOGIC MECHANISMS}

The widely held pathophysiologic hypotheses for both Huntington's chorea and tardive dyskinesias are based on the belief that certain dopaminergic receptors in the striatum have become hypersensitive. In tardive dyskinesias the pathophysiologic mechanism is believed to be similar to a chemical denervation hypersensitivity of the dopaminergic nerve endings following prolonged receptor blockade by neuroleptics. ${ }^{30}$ In Huntington's chorea the hypersensitivity is believed to be the result of the degenerative process of the disease. ${ }^{31}$ Is it possible that when one treats a Huntington's chorea patient with neuroleptics one is actually exacerbating the preexisting hypersensitivity or causing a tardive dyskinesia in addition to the already present hereditary chorea? This question should be paramount even though there is no alternative at the present time to the palliative treatment with neuroleptics.

\section{PRESUMPTIVE PHARMACOLOGIC DIAGNOSTIC TESTS}

Despite some recent interesting findings in this area, there is still no presumptive pharmacologic diagnostic test to differentiate between Huntington's chorea and tardive dyskinesia. Interestingly, most agents that either improve or exacerbate one disorder also have the same effect on the other. For example, L-dopa, which is presently being tried as a diagnostic agent in asy mptomatic individuals at risk for Huntington's chorea, ${ }^{32}$ has been shown to exacerbate the movement disorders in both Huntington's chorea and tardive dyskinesia. ${ }^{29}$ Furthermore, there are reports in the literature indicating that a drug holiday exacerbates the movements in tardive dyskinesia, while the resumption of neuroleptics at the same dose level or a sudden increase in dose will cause a temporary improvement. ${ }^{30}$ These same phenomena have been standard clinical observations in Huntington's chorea. Another recent observation that has caused a great deal of interest involves the use of a Gaba analogue. The early results with Gaba indicate that Huntington's patients can tolerate the analogue at moderate doses, while 
control subjects cannot. ${ }^{33}$ It is not known as yet how tardive dyskinesia patients would respond to the Gaba analogue or even if they have low Gaba levels (see the discussion below on Gaba levels in Huntington's chorea). Physostigmine salicylate has been shown to cause some alleviation of symptoms in Huntington's chorea, ${ }^{31}$ and anticholinergic medications have caused exacerbations of symptoms in both. ${ }^{24}$ Recently there have been preliminary reports in the literature as to apomorphine's effectiveness in the treatment of acutely induced neuroleptic dyskinesias, ${ }^{34}$ tardive dyskinesias, and Huntington's chorea. ${ }^{35}$ Thus the results of various trials with pharmacologic agents have furthered the belief that there are similar mechanisms involved in both Huntington's chorea and tardive dyskinesias and have not advanced our ability to differentiate these two disorders.

\section{NEUROCHEMICAL FINDINGS}

As mentioned above, the Gaba findings in Huntington's chorea have generated a great deal of interest. Gaba or $\gamma$-aminobutyric acid is a proposed neurotransmitter that has been shown to be released from mammalian brain surfaces during inhibitory activity or after stimulation of subcortical regions. ${ }^{33}$ Gaba levels in the extrapyramidal system of patients with Huntington's chorea have been shown to be reduced significantly. ${ }^{31}$ Gaba levels in patients with tardive dyskinesia have yet to be investigated.

Early reports in the literature indicated that CSF homovanillic acid (HVA) concentrations were within normal limits in tardive dyskinesia ${ }^{24}$ and were normal or slightly decreased in Huntington's chorea. ${ }^{33}$ However, "more detailed recent regional determinations ... now indicate that caudate dopamine and HVA cncentrations are significantly decreased" in Huntington's chorea. ${ }^{33}$ Patients with this disorder at postmortem also had "markedly less average choline acetylase activity in the caudate and putamen" 31 than did a normal group of controls. Furthermore, brains from Huntington's chorea patients have had relatively reduced GAD (glutamic acid decarboxylase), the enzyme responsible for Gaba synthesis and reduced activities in the caudate, putamen, globus pallidus, and substantia nigra, while the tyrosine hydroxylase concentration was not found to be reduced. ${ }^{31}$ The values of choline acetylase, GAD, and tyrosine hydroxylase in brain of tardive dyskinesia patients are not known. The serum ceruloplasmin values in patients with Huntington's chorea have been reported to be low, ${ }^{33}$ while again the value of this chemistry in dyskinesias is not known.

\section{RADIOGRAPHIC AND POSTMORTEM FINDINGS}

Blinderman et al., reporting in 1964 on the pneumoencephalograms of eight patients with Huntington's chorea, stated that the radiographic appearance varied from being normal to showing characteristic atrophy of the caudate and putamen. ${ }^{36}$ They found that there was no clinical correlation of severity or duration of the illness with the radiographic appearance and concluded that the presence of a normal pneumoencephalogram does not rule out a diagnosis of Huntington's chorea. However, Gath and Vinje, ${ }^{37}$ reporting in 1968 on a Huntington's chorea patient population of 36 , found an increased width of the ven- 
tricular bodies in the majority of cases, while the frontal horns did not appear specifically enlarged. Furthermore, "although no clear correlation was found between the degree of the radiologic findings and the severity of clinical symptoms, all of the patients with severe mental changes were found to have severe enlargement of the ventricular body." ${ }^{37}$ A postmortem study by Christensen et al. ${ }^{38}$ revealed that 3 brains (out of 28 ) from patients who had dyskinesias before their deaths and 3 brains from controls without dyskinesias before their deaths (also out of 28) demonstrated encephalomalacic processes in the caudate nuclei and that 18 of the dyskinetic and 14 of the control brains demonstrated gliosis in the caudate nuclei. What would the pneumoencephalograms of these dyskinetic patients have looked like? Might there not have been the appearance of enlarged ventricular bodies secondary to the atrophy of the caudates? Young and Crampton found that 24 of their sample of 36 schizophrenic patients had clear cerebral atrophy and that "the incidence of atrophy in middle-aged hospitalized patients was as high as that found in neurological patients in whom atrophy had been expected." 39 As yet there has been no reported study of the pneumoencephalographic findings in tardive dyskinesia.

At present it is unclear if the CAT (computerized axial tomography scan) findings in Huntington's chorea and tardive dyskinesia will be helpful in distinguishing one disorder from the other.

\section{OTHER FINDINGS}

One interesting finding is that in both Huntington's chorea and tardive dyskinesia there is an impairment of the optokinetic nystagmus. ${ }^{40}$ It has also been reported that Huntington's chorea patients have an inability to make rapid eye movements in all oculomotor activities ranging from voluntary to reflexively elicited movements. ${ }^{29}$ Disturbances of ocular motility in tardive dyskinesia patients, other than optokinetic reflexes, have not been reported.

\section{CONCLUSION}

The diagnosis of Huntington's chorea is clear in cases with positive family history for the disorder and a progressive deterioration of the patient marked by choreiform movements and psychologic symptoms resulting in dementia. Similarly, the diagnosis of tardive dyskinesia is clear in cases where there is no family history of Huntington's chorea and where the patient had been using neuroleptics before developing dyskinesias. Unfortunately, many cases fall within the continuum between these two clear-cut clinical pictures. It is in this area that caution must be exercised to avoid the pitfalls of a hasty diagnosis, as there are numerous similarities between these two disorders. It is concluded that in many cases a definitie diagnosis may not be possible. Further work in the areas of comparative neurochemistries, neuropathology, neuropharmacology, and pneumoencephalography will be necessary in order to make this differential diagnosis more easily. Finally, the author submits the disconcerting possibility that Huntington's chorea patients treated with neuroleptics may be especially prone to develop tardive dyskinesia in addition to their al ready present hereditary choreas. 


\section{ACKNOWLEDGMENT}

The author is grateful to Bernard Carroll, M.D., Ph.D. for his help and support in writing this article.

\section{REFERENCES}

1. Crane GE: Persistent dyskinesia. Br J Psychiatry 122:395-405, 1973

2. Degkwitz R: Uber die Ursachen der persistierenden extrapyramidalen Hyperkinesen nach langfristiger Anwendung von Neuroleptika. Acta Nerv Sup Scpt. 1967, pp 389-399

3. Heinrich K, Wegener I, Bender HJ: Spate extrapyramydale Hyperkinesen bei neuroleptisher Langzeit-therapie. Pharmakopsychiatrie, Neuro-Psychopharmakologie 1:169-195, 1968

4. Kennedy PF, Hershon HI, McGuire RJ: Extrapyramidal disorders after prolonged phenothiazine therapy. Br J Psychiatry 118:509518,1971

5. Turunen S, Achte KA: The bucco-lingualmasticatory syndrome as side effect of neuroleptic therapy. Psychiatr Q 41:268-280, 1967

6. Villeneuve A, Lavallee JC, Lemieux LH: Dyskinesie tardive post-neuroleptique. Laval Medical 40:832-837, 1969

7. Lehmann HL, Ban TA, Saxena BM: A survey of extrapyramidal manifestations in the in-patient population of a psychiatric hospital. Laval Medical 41:909-916, 1970

8. Brandon S, McClelland HA, Protheroe C: A study of facial dyskinesia in a mental hospital population. Br J Psychiatry 118:171-184, 1971

9. Crane GE: Dyskinesia and neuroleptics. Arch Gen Psychiatry 19:700-703, 1968

10. Crane GE: High doses of trifluperazine and tardive dyskinesia. Arch Neurol 33:176-180, 1970

11. Hippius H, Lange J: Zur Problematik der spaten extrapyramydalen Hyperkinesen nach langfristiger neuroleptisher Therapie. Arzneim Forsch 20:888-890, 1970

12. Fann WE, Davis JM, Janowsky DS: The prevalence of tardive dyskinesia in mental hospital patients. Dis Nerv Syst 33:182-186, 1972

13. Greenblatt DL, Stotsky BA, DiMascio A: Phenothiazine-induced dyskinesia in nursing home patients. J Am Geriatr Soc 16:24-34, 1968

14. Edwards $H$ : The significance of brain damage in persistent oral dyskinesia. $\mathrm{Br} \mathbf{J}$ Psychiatry 116:271-275, 1970

15. Pryce IJ, Edwards H: Persistent oral dyskinesia in female mental hospital patients. $\mathrm{Br} \mathrm{J}$ Psychiatry 112:983-987, 1966

16. George GE: Neuroleptics and proneness to motor disorders. Scientific Proceedings (abstracts), 124th Annual Meeting, American Psychiatric Association, 1971, pp 112-113

17. Myrianthopoulos NC: Huntington's chorea: The genetic problem five years later, in: Advances in Neurology, vol 1. New York, Raven Press, 1973, p 150

18. Wallace DC, Parker N: Huntington's chorea in Queensland: The most recent story, in: Advances in Neurology, vol 1. New York, Raven Press, 1973, p 225

19. Garron DC: Huntington's chorea and schizophrenia, in: Advances in Neurology, vol 1. New York, Raven Press, 1973, p 730

20. Gunderson JG, Autry JH, Mosher LR: Special report--schizophrenia-1973. Schizophrenia Bulletin 9:15-54, 1974

21. Palm JD: Longitudinal study of a preclinical test program for Huntington's chorea, in: Advances in Neurology, vol 1. New 'York, Raven Press, 1973, pp 31 1-324

22. A.N.C.P.-F.D.A. Task Force: Neurological syndromes associated with anti-psychotic drug use-A special report. Arch Gen Psychiatry 28:463-467, 1973

23. Crane GE, Naranjo ER: Motor disorders induced by neuroleptics. Arch Gen Psychiatry 24:179-184, 1971

24. Klawans HL Jr: The phar macology of tardive dyskinesias. Am J Psychiatry 130:82-86, 1973

25. Stevens DL: The classification of variants of Huntington's chorea, in: Advances in Neurology, vol 1. New York, Raven Press, 1973, pp 57-64

26. Ayd FJ Jr: Persistent dyskinesia: A neurologic complication of major tranquilizers. Medical Science 18:32-40, 1967

27. Degkwitz R, Wenzel W: Persistent extrapyramidal side effects after long-term application of neuroleptics, in Brill $\mathrm{H}$, Cole JO, Deniker P, et al (eds): Neuropsychopharmacology (International Congress Series 129). Amsterdam, Mouton and Co., 1967

28. Ringel SP, Guthrie M, Klawans HL Jr: Current treatment of Huntington's chorea, in: Advances in Neurology, vol 1. New York, Raven Press, 1973, p 797

29. Crane GE: Tardive dyskinesia and Huntington's chorea: Drug-induced and hereditary 
dyskinesias, in: Advances in Neurology, vol 1. New York, Raven Press, 1973, p 117

30. Kazamatsuri H, Chien C, Cole JO: Therapeutic approaches to tardive dyskinesia. Arch Gen Psychiatry 27:491-499, 1972

31. McGeer PL, McGcer EG, Fibiger HC: Choline acetylase and glutamic acid decarboxylase in Huntington's chorea: A preliminary study. Neurology 23:912-917, 1973

32. Klawans HL Jr, Paulson GW, Ringel SP, Barbeau A: The use of L-dopa in the presymptomatic detection of Huntington's chorea, in: Advances in Neurology, vol 1. New York, Raven Press, 1973, p 295

33. Barbeau A: The biochemistry of Huntington's chorea: Recent developments. Psych Forum Fall, 1973, pp 8-14

34. Gessa R, Tagliamonte A, Gessa GL: Blockade by apomorphine of haloperidol induced dyskinesia in schizophrenic patients. Lancet Nov 4, 1972, pp 981-982
35. Tolosa ES: Paradoxical suppression of chorea by apomorphine. (letters) JAMA 299:1579-1580, 1974

36. Blinderman EE, Weidner W, Markham $\mathrm{CH}$ : The pneumoencephalogram in Huntington's chorea. Neurology 14:7, 1974

37. Gath I, Vinje B: Pneumoencephalographic findings in Huntington's chorea. Neurology $18: 991-996,1968$

38. Christensen E, Moller JE, Faurbye A: Neuropathological investigation of 28 brains from patients with dyskinesia. Acta Psychiatr Scand 46:14-23, 1970

39. Young IJ, Crampton AR: Cerebrospinal fluid uric acid levels in cerebral atrophy occurring in psychiatric and neurologic patients. Biol Psychiat ry 8:281 291, 1974

40. Lipper S: Impairment of optokinetic nystagmus in patients with tardive dyskinesia. Arch Gen Psychiatry 28:331-333, 1973 